\title{
ASO Visual Abstract: Infiltrative Tumor Borders in Colorectal Liver Metastasis: Should We Enlarge Margin Size?
}

Vitoria Ramos Jayme, MD ${ }^{1}$, Gilton Marques Fonseca, MD PhD ${ }^{1}$, Isaac Massaud Amim Amaral, MD ${ }^{1}$, Fabricio Ferreira Coelho, MD PhD ${ }^{1}$, Jaime Arthur Pirola Kruger, MD PhD ${ }^{1}$, Vagner Birk Jeismann, MD ${ }^{1}$, Rafael Soares Nunes Pinheiro, MD PhD ${ }^{1}$, Evandro Sobroza de Mello, MD PhD ${ }^{2}$, and Paulo Herman, MD PhD ${ }^{1}$

${ }^{1}$ Liver Surgery Unit, Digestive Surgery Division, Department of Gastroenterology, Hospital das Clinicas, University of Sao Paulo School of Medicine, Sao Paulo, Brazil; ${ }^{2}$ Department of Pathology, Hospital das Clinicas, University of Sao Paulo School of Medicine, Sao Paulo, Brazil

In colorectal liver metastasis, histopathological features have been reported as prognostic factors, including metastatic tumor growth pattern. We analyzed the prognosis of patients with resected colorectal liver metastasis according to the tumor growth pattern and its relationship with margin size (https://doi.org/ 10.1245/s10434-021-09916-w).

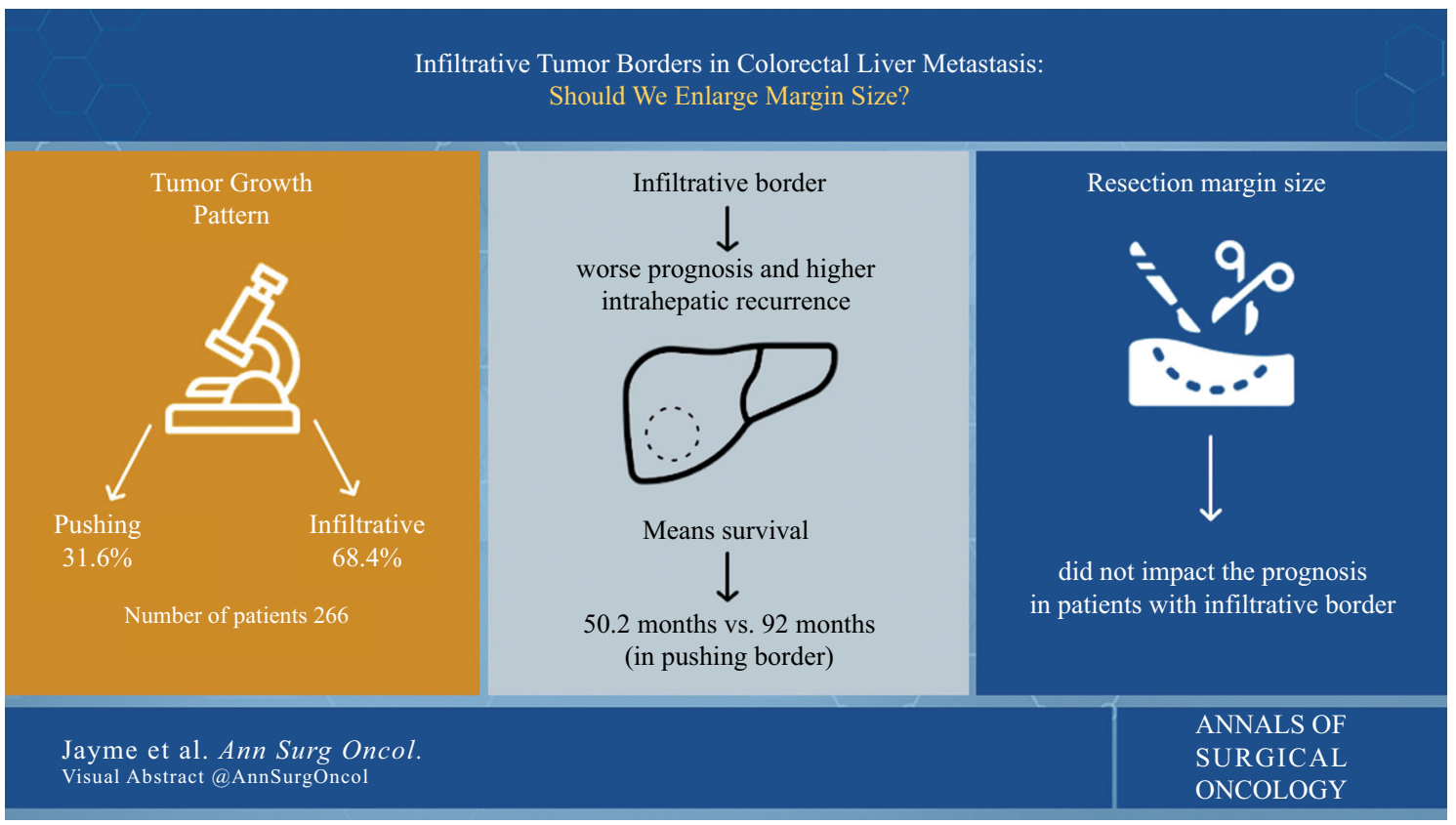

(C)

V. R. Jayme, MD

e-mail: vitoriarjayme@hotmail.com

Publisher's NoteSpringer Nature remains neutral with regard to jurisdictional claims in published maps and institutional affiliations. 